\title{
Red in the Development of Sports in Colleges and Universities Sports Education to Promote Study
}

\author{
Xueda Yang \\ yanan university sports institute, yanan, shaanxi, China \\ E-mail:yangxueda1976@163.com
}

Keywords: red sports; college sports; development alienation

\begin{abstract}
Using the literature material method, logic method and dialectical analysis and other research methods, based on the status of red sports and the perspective of value, interpretation of the alienation phenomenon of sports education in colleges and universities in our country, to red sports education in colleges and universities sports education value, through the red sports spirit helps cultivate and carry forward the spirit of the Chinese sports college students, set up the socialism outlook for honor and dishonor, promote the development of the university sports morality, the firm ideal faith, form physical education concept of scientific development, peopleoriented to realize the harmonious development of university sports.
\end{abstract}

\section{Introduction}

Under the correct leadership of the communist party of China, China's red sports is a glorious chapter of the history of China. However, in the development and reform under the background of economic globalization, various social ideological trend of unprecedented active collision, money worship, hedonism, and personal heroism and other western countries in the field of ideology of sports values have impact, bring about age in the university sports education training and competition, an impostor, borrow the professional athletes, ignoring the field discipline, fighting, bribes, and many other sports dissimilation phenomenon. The quality of university students will directly affect the realization of the great rejuvenation of the Chinese nation. In sports in colleges and universities, therefore, to strengthen the red sports spirit, is a high-quality education resources, not only can make college students fitness, enhance ability to resist setback, and can give full play to the characteristics of physical education, exerts a lively red, promote the university students to form scientific and healthy value system, the harmonious development of physical education in colleges and universities and realize China's dream has very important significance.

\section{Organization of the Text}

\section{A. Red red culture and sports}

1) The red culture connotation.Red culture is since the founding of the communist party of China, from the concrete practice in our country, dominated by marxism and led the Chinese people of all ethnic groups in the struggle for national independence and liberation of revolutionary practice, and in the construction of socialism with Chinese characteristics, and constantly in the process of reform and opening up, restructuring, integration of Chinese and foreign excellent cultural ideas on the basis of the formation of the great revolutionary spirit and its carrier. It vividly reflects the people under the leadership of the communist party of China, in the agrarian revolution, the Anti-Japanese War, liberation war emerge the advanced character of the great personality, revolutionary deeds and noble spirit, is an important part of the advanced culture of socialism with Chinese characteristics, a precious spiritual wealth of the Chinese people and national survival and development power of [1].

2) Red sports connotation. Red sports, in a narrow sense, red sports mainly refers to the ruijin central Soviet area and then to yan 'an as the center of the shensi-kansu-ningsia border region sports. From the broad sense, from the founding of the communist party of China, and the establishment of the 
Soviet regime, led by the communist party of China the toiling masses of self-appointed sports, known as red sports. This study argues that began in the may fourth movement to the founding of new China (1919-1949) of the new-democratic revolution period, under the leadership of the communist party of China, to the toiling masses as the main body, the people of the new mass sports activities, sports are collectively referred to as red. Under the leadership of the communist party of the red sports is an indispensable part of modern sports history, for after the liberation of sports has the function of the dimensions of [1].

\section{$B$ Red sports history status and contemporary value}

Red sports as an important component of the new democratic culture, whether in the past, present or future, has a huge irreplaceable value, for the new China sports sports cadres and provides referential pattern, for the school sports has carried on the beneficial exploration of new China, left a valuable revolutionary tradition spirit, opened up the road of socialism with Chinese characteristics sports. [2] in red sports under the leadership of the communist party of China's basic situation, learn the valuable experience and tradition, the young generation in the new period patriotic tradition education, for the construction of a harmonious socialist society and the harmonious development of the college sports are very important and urgent practical significance [3]

\section{$C$ Dissimilation phenomenon in the process of college sports development}

Value and role of college physical education has been widely recognized the social from all walks of life, it is widely expected to assume the burden of students physical health college sports, to cultivate comprehensive senior talents for the society to contribute, however, from the practical perspective of current our country university sports development, did not realize the society and people's enthusiasm for sports development in colleges and universities, and even a departure from the current college sports "health first" the phenomenon of "lifetime sports" principle, to this end, we have to the actual survey and reflection of the current college sports development, alienation phenomenon of deviating from the college sports development objective research and analysis.

1) Too much with the students for this phenomenon is serious.In the process of school sports development, also often appear some contrary to the nature of school sports phenomenon, such as: PE is transformed into "activity", "sheep class" and so on, the dissimilation phenomenon hindered the upward development of school sports. In the face of social public opinion, how to deal with the crisis of confidence the school physical education is an urgent need to solve the problem. College sports teaching emphasis on people-oriented is to face up to the individual differences between students, to students according to their aptitude, give full play to each person's potential and expertise. But part of college sports teachers will be "people-oriented" the connotation of the one-sided distortion for the "student-centered", excessive highlight the students' interest in physical education curriculum teaching process, willingness, and nature, and neglect, reduced or eliminated the teacher in the necessary position in the physical education curriculum teaching and guidance role. [1] and now most of the students who is an only child, from an early age by family "care", the lack of education bears hardships and stands hard work, to the thing judgment is not yet complete, correct, many children indolence, a slight difficulty and intensity of movement is bound by many students in a variety of reasons not to participate in, and not willing to bear the phenomenon, and red sports spirit presents us is strong will quality, far, afraid tired, give us the lack in the university sports education the beneficial supplement, with red sports spirit infection and incentive and promote college students to form healthy exercise value system of science.

2) Excessively exaggerating the role of sports. College students are the hope of country and nation, their healthy growth is related to the whole nation's survival, is related to the realization of the great Chinese dream. The development of nearly 40 years of reform and opening-up, our country competitive sports, national economy and people's living standards have been greatly improved, why normal military training, playing basketball, running, sudden death sudden death, sudden death, committed suicide by jumping off a building, etc. We see an endless cervix sudden death? Why the students' physique worse and worse? The central file points out that led to the decrease of the 
students' physical health level 7 there are two reasons, one is takes an exam the education to pursue graduation rates influence, social and school regards the intellectual light body is serious, on the other hand is the insufficient sports facilities and conditions. Society has always been the students physical deterioration in relation to the school sports, school sports thought to be bad. If the only reason for students' physical health level decline due to the school sports work, I'm afraid some one-sided, and from that enhances students' physical health level, school sports also won't undertake the task alone. Admittedly, there are the factors of school sports, but can't boil down to the problem of responsibility of the school sports. Especially in recent years, part of college sports teachers and workers, infinite extension and exaggerated the school physical education, the function of the sunshine sports in the "health first", her health problems have come to school sports head, make the school sports, sports is one of the many factors that affect health, is to promote health is a good method.

3) The status of sports has always been marginalized.Sports in the universities sports teaching also undertake the task of the cultural inheritance and dissemination, various also relatively complete system of rules and regulations construction, why is it important to do a secondary, busy don't phenomenon common occurance? We have been emphasized facilities are insufficient or do not amount to mark, but the facilities condition is up to standard, update or the status of our school sports in society increased? On the contrary, if the facility site condition were up to standard while the physical health of students aren't up to standard, school sports have a problem again? Why didn't red sports venues, equipment and facilities during the period of high degree of standards is getting involved? People bear hardships and stand hard work spirit is present everywhere? Especially in yanan period of school sports, adjust measures to local conditions, roughing, has a clear physical properties, goals and characteristics, from the aspects such as physical education, extracurricular sports activities, sports competitions content pragmatic, flexible and varied in form, extensive participation, enthusiasm high, no matter from the guiding ideology, management system, teaching practice may provide reference for school sports today. I feel that we are from the big ideas of reform on the problem, that is to say the problem is not unilateral, parents, students, education system, curriculum and teachers themselves.

4)Security became the threshold of the sports. To be on the safe side, most colleges and universities sports meeting has been canceled $3000 \mathrm{~m}, 5000 \mathrm{~m}$ run traditional items, in order to avoid risk and will not affect the academic, almost all of our physical education is based on "no sweat, no dirty clothes, no pant, not injured, not long-distance running, wrestling, erasers, no intensity, no fighting, no collision of" 357 "not gentle sports, have such sports can strengthen body, temper? Can shape a complete personality? If a country's university students regard a mere eight hundred thousand meters be afraid, for the sake of so-called "security" easily give in to weak demand, and this kind of concessions had agreed by many parents, teachers, principals, the whole society doesn't even have some doubts, then the Chinese man and his country's military will come from? One of the students from primary, secondary to the 14 years on the university P.E. classes (1404 hours), may finally graduated from the university, don't even understand basic sports knowledge, more don't talk about by physical education to develop lifelong sports consciousness. Why learn a driver's license a few months to pick up, and will benefit for life, that can't drive is dangerous?

As a school to support their students to participate in sports, as a teacher to understand their own responsibilities and tasks; As parents should encourage children to participate in sports, make sports education, make sports play a function to eliminate the peoples prejudice to the sports education, cultivate people's pursuit and yearning to sports. Vaginal a development law of human action master students actively and develop their motor skills, develop the students' active exercise consciousness, through the various experience of physical activity, form the positive value orientation, behavior and social norms, promote the development of physical and mental health.

$D$ Red in the process of development of sports in colleges and universities sports education value

1)Helps to cultivate the Chinese national sports spirit.The Chinese sports spirit in the tradition of the Chinese traditional culture and marxist thought organic holism thought, has for the collective,Ethnic 
and national honor, indomitable cultural connotation, scaling new heights, unity and mutual assistance, and all the red sports based on revolutionary war hero and touching story, etc. These elements of the "red", fully tap the mental function of the formed in the specific historical period, through vivid deeds and noble personality influence infection, will have to be red sports sound national spirit, the spirit, the spirit of the Chinese sports education in the socialist core value system education, to strengthen college students' national self-esteem, self-confidence and a sense of pride, helps to promote college students' patriotic emotion, innovation spirit and the spirit of the Chinese sports, forming characteristics of red sports culture in colleges and universities in the new period [1].

2 ) Helps to form a university sports scientific development.Red sports were marked a period of history, shows a kind of spirit, found a realistic way for China to popularize sports. In the impact of western culture and values and long-term under the influence of the system of competitive sports, competitive sports dissimilation "gold medal first", "for this" the object value orientation, induce people to materialistic inflation, all kinds of black whistle, match-fixing, gambling with sport in China, the athletes of the state, collective, social responsibility decreased significantly. Some college students lack of ideal and faith Not only brings serious harm on college students' physical and mental health, also constitute a great threat to the revival of the Chinese nation. To the teaching of the red sports spirit, and let students grasp to the martyrs in the immersive revolution to a strong, prosperous, the rise of the Chinese nation and the history of massiness, and help students to achieve the ideal of socialism with Chinese characteristics faith, realize the harmonious development of sports in colleges and universities.

\section{Conclusions}

Red sports resources and in the campus network, the red sports culture resources as the main position of the campus network, to make it become the mainstream of college campus culture, network times make the red culture especially red sports culture spread in the whole college campus, in order to improve college students' socialist core values. Reasonable and effective development of red resources, pay attention to the integrity of the red sports resources and take joint system, dynamic development model, make the red sports resources to maintain continuity, play to the overall effect. At the same time, combining the development and protection, through education and development, tourism development, industrial development and the way of development of archives, to adopt new technology, constantly promoting innovation and red sports resources advantage, make the red sports culture into a patriotic education of college students, and promote the healthy development of the high quality of PE course resources.

\section{References}

[1] xian-jun liu. Analyze the red sports education in college students' socialist core value system in value [J], modernization shopping mall, 2012:226-22.

[2] party quite, danger heavy dry. Nearly 60 years research analyzes red sports in China [J], journal of Shanghai sports institute, 2010, 7:21-24.

[3] Liu Xian xiao-zheng xiong. Red sports cultural thoughts of history and development [J], journal of Beijing sports university, 2012, 2:29-34. 